NEW ZEALAND BUILT ENVIRONMENT RESEARCH SYMPOSIUM

Shaping future directions for collaborative built environment research and practice in New Zealand

\title{
Application of nD BIM Integrated Knowledge-based Building Management System (BIM-IKBMS) for Inspecting the Post-Construction Energy Efficiency
}

\author{
Ali GhaffarianHoseini ${ }^{1}$, John Tookey ${ }^{2}$, AmirHosein GhaffarianHoseini ${ }^{3}$ \\ ${ }^{1 \& 2}$ School of Engineering, Faculty of Design and Creative Technologies, AUT University, Auckland, New \\ Zealand \\ ${ }^{3}$ Department of Geography, Faculty of Arts and Social Sciences, University of Malaya, Kuala Lumpur, \\ Malaysia.
}

\section{ABSTRACT}

The evolution of construction industry towards sustainability highlighted the absolute necessity to inspect sustainable performances throughout the post-construction building lifecycle. Correspondingly, application of relevant building management systems (BMS) to achieve this goal is mandatory (Ippolito, Riva Sanseverino, \& Zizzo, 2014). In addition, conventional post-construction building inspection methods are outdated and less effective. Therefore; this research aims to propose specific utilization of BIM during building maintenance for the consequential post-construction energy efficiency.

Contemporarily, Building Information Modelling (BIM) is considered as a leading technology capable of being utilized in Architecture, Engineering, Construction (AEC) practices highlighting its critical role in enhancing the effectiveness of project delivery from conceptual initiation to eventualization and even post-construction maintenance (Ding, Zhou, \& Akinci, 2014; Volk, Stengel, \& Schultmann, 2014). Alternatively, despite the recent presentation of BIM to the AEC industry, it has widely emerged to an undisputedly contributive technology towards advancement of AEC implementations. Furthermore, BIM's capability of nD project integrations has prominently highlighted its potential effectiveness while being accurately incorporated with sustainable performances (Farr, Piroozfar, \& Robinson, 2014). Moreover, researchers have highlighted that information gathering and modelling through BIM can reduce respective building energy consumptions (Lawrence et al., 2012).

The remarkable proportion of global energy consumption by the construction industry has fundamentally driven the concentration on decreasing the building energy consumption via amplified sensor data and improved computational support for building controls (Klein et al., 2012). Subsequently, it is vital to balance the maximization of building energy efficiency and users' desired level of comfort while employing an efficient BMS for sustainable maintenance of facility operations overstressing the implication of post-construction building inspection.

Researchers have overstressed that application of an efficient Facility Maintenance and Management systems (FMM) enables executives to detect problems primarily and sustain the facility more effectively (Chen, Hou, \& Wang, 2013). On the other hand, the conventional inspection method of progress tracking practice would solely

GhaffarianHoseini, A., Tookey, J., GhaffarianHoseini, A.M. (2014). Application of nD BIM Integrated Knowledge-based Building Management System (BIM-IKBMS) for Inspecting the Post-Construction Energy Efficiency. Proceedings of the 4th New Zealand Built Environment Research Symposium (NZBERS). Auckland, New Zealand. 14 November. ISSN 2324-1829 (Online). 
rely on manual visual assessments and periodical respective reports. This progress consisted of logs and checklists manually prepared to indicate the project's level of adaptability with the required milestones and specifications (Bosché, Ahmed, Turkan, Haas, \& Haas, 2014). Effectiveness and accuracy of the corresponding inspection progress would have been affected based on the individual's personal judgment and observational skills. Additionally, high probability of inaccurate manual building inspections plus the lack of real-time input of dynamic factors urges development of automated BMS. Therefore, Building Information Modelling (BIM) plays a key role towards automation in construction and corresponding management systems. However, adequate skills; competence and enthusiasm of construction role-players and contractors is a significantly important issue towards future success of such propositions (Miettinen \& Paavola, 2014).

Additionally, the progression of AEC building delivery includes design, construction, contracting and maintenance. This complex process, engaging multi-layer and multi-domain information storage and exchange, necessitates integrative contributions from versatile and incorporative professional teams thus; competent information sharing among players is a critical factor towards success therefore; a proposed BIM system capable of resolving AEC interoperability complications would remarkably enhance the overall project output and respectively the building energy efficiency throughout its lifecycle (Dong, O'Neill, \& Li, 2014).

Despite the $\mathrm{nD}$ capability of BIM enabling its potential practice during versatile building lifecycle phases, designers-contractors focused primarily on the application of BIM during design-construction management stages. Furthermore, positive prospects of BIM's potential to be applied throughout the post-construction energy efficiency enhancements can be augmented while highlighting the conceivable successful utilization of BIM during corrective building maintenance management concerns compared to preventive concerns (Motawa \& Almarshad, 2013).

Moreover, integration of knowledge management systems empowering handling and sharing of respective building maintenance information over the building lifecycle is an inevitable essential during post-construction sustainable performances. Harmoniously, contemporary sustainable developments incorporate advancement of exploiting the aforementioned practices. Congruently, focusing on the building energy efficiency, this article suggests engagement of an Integrated Knowledge-based Building Management System using nD BIM applications (BIM-IKBMS) during the post-construction building lifecycle to advance the implementation of sustainable building performances.

\section{Keywords}

Building Information Modelling; Building Management System; Post-construction Lifecycle; Energy Efficiency; $n$ Dimensional Implementations 


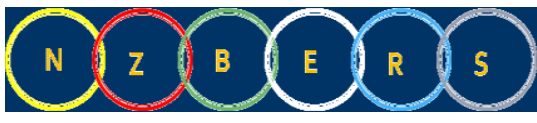

NEW ZEALAND BUILT ENVIRONMENT RESEARCH SYMPOSIUM

Shaping future directions for collaborative built environment research and practice in New Zealand

GhaffarianHoseini, A., Tookey, J., GhaffarianHoseini, A.M. (2014). Application of nD BIM Integrated Knowledge-based Building Management System (BIM-IKBMS) for Inspecting the Post-Construction Energy Efficiency. Proceedings of the 4th New Zealand Built Environment Research Symposium (NZBERS). Auckland, New Zealand. 14 November. ISSN 2324-1829 (Online). 


\section{References}

Bosché, F., Ahmed, M., Turkan, Y., Haas, C. T., \& Haas, R. (2014). The value of integrating Scan-to-BIM and Scan-vs-BIM techniques for construction monitoring using laser scanning and BIM: The case of cylindrical MEP components. Automation in Construction(0). doi: http://dx.doi.org/10.1016/j.autcon.2014.05.014

Chen, H.-M., Hou, C.-C., \& Wang, Y.-H. (2013). A 3D visualized expert system for maintenance and management of existing building facilities using reliability-based method. Expert Systems with Applications, 40(1), 287-299. doi: http://dx.doi.org/10.1016/j.eswa.2012.07.045

Ding, L., Zhou, Y., \& Akinci, B. (2014). Building Information Modeling (BIM) application framework: The process of expanding from 3D to computable $\mathrm{nD}$. Automation in Construction, 46(0), 82-93. doi: http://dx.doi.org/10.1016/j.autcon.2014.04.009

Dong, B., O'Neill, Z., \& Li, Z. (2014). A BIM-enabled information infrastructure for building energy Fault Detection and Diagnostics. Automation in Construction, 44(0), 197-211. doi: http://dx.doi.org/10.1016/j.autcon.2014.04.007

Farr, E. R. P., Piroozfar, P. A. E., \& Robinson, D. (2014). BIM as a generic configurator for facilitation of customisation in the AEC industry. Automation in Construction, 45(0), 119-125. doi: http://dx.doi.org/10.1016/j.autcon.2014.05.012

Ippolito, M. G., Riva Sanseverino, E., \& Zizzo, G. (2014). Impact of building automation control systems and technical building management systems on the energy performance class of residential buildings: An Italian case study. Energy and Buildings, 69(0), 33-40. doi: http://dx.doi.org/10.1016/j.enbuild.2013.10.025

Klein, L., Kwak, J.-y., Kavulya, G., Jazizadeh, F., Becerik-Gerber, B., Varakantham, P., \& Tambe, M. (2012). Coordinating occupant behavior for building energy and comfort management using multi-agent systems. Automation in Construction, 22(0), 525-536. doi: http://dx.doi.org/10.1016/j.autcon.2011.11.012

Lawrence, T. M., Watson, R. T., Boudreau, M.-C., Johnsen, K., Perry, J., \& Ding, L. (2012). A new paradigm for the design and management of building systems. Energy and Buildings, 51(0), 56-63. doi: http://dx.doi.org/10.1016/j.enbuild.2012.04.016

Miettinen, R., \& Paavola, S. (2014). Beyond the BIM utopia: Approaches to the development and implementation of building information modeling. Automation in Construction, 43(0), 84-91. doi: http://dx.doi.org/10.1016/j.autcon.2014.03.009

Motawa, I., \& Almarshad, A. (2013). A knowledge-based BIM system for building maintenance. Automation in Construction, 29(0), 173-182. doi: http://dx.doi.org/10.1016/j.autcon.2012.09.008

Volk, R., Stengel, J., \& Schultmann, F. (2014). Building Information Modeling (BIM) for existing buildings Literature review and future needs. Automation in Construction, 38(0), 109-127. doi: http://dx.doi.org/10.1016/j.autcon.2013.10.023 